03,13

\title{
Влияние адсорбции атомов натрия и прогрева на наночастицы золота, адсорбированные на вольфраме
}

\author{
(ㄱ П.А. Дементьев ${ }^{1}$, Е.В. Иванова ${ }^{1}$, М.Н. Лапушкин ${ }^{1}$, Д.А. Смирнов ${ }^{2}$, С.Н. Тимошнев ${ }^{3}$ \\ ${ }^{1}$ Физико-технический институт им. А.Ф. Иофрфе РАН, \\ Санкт-Петербург, Россия \\ ${ }^{2}$ Institut für Festkörper- und Materialphysik, Technische Universität Dresden, \\ 01062 Dresden, Germany \\ ${ }^{3}$ Санкт-Петербургский национальный исследовательский Академический университет им. Ж.И. Алфёрова РАН, \\ Санкт-Петербург, Россия \\ E-mail: lapushkin@ms.ioffe.ru
}

Поступила в Редакцию 27 марта 2020 г.

В окончательной редакции 27 марта 2020 г.

Принята к публикации 2 апреля 2020 г.

\begin{abstract}
Проведены исследования методом фотоэлектронной спектроскопии in situ в сверхвысоком вакууме электронной структуры наночастиц золота, напыленных на поверхность вольфрама, до и после адсорбции атомов натрия a c последующим прогревом при $T=630 \mathrm{~K}$. Изучены спектры фотоэмиссии из валентной зоны и остовных уровней $\mathrm{Au} 4 f$ и $\mathrm{Na} 2 p$ при синхротронном возбуждении в диапазоне энергий фотонов 80-600 eV. Показано, что изменения в спектрах валентной зоны и остовных уровней Аu $4 f$ и $\mathrm{Na} 2 p$ связаны с изменением топографии поверхности, вызванным адсорбцией атомов натрия и прогревом, которые привели к увеличению площади поверхности в несколько раз. Исследованы топография поверхности и катодолюминесценция слоя золотых наночастиц, напыленных на поверхность вольфрама.
\end{abstract}

Ключевые слова: наночастицы золота, адсорбция, натрий, фотоэмиссия, АСМ, катодолюминесценция.

DOI: $10.21883 /$ FTT.2020.08.49597.071

\section{1. Введение}

Современные достижения в области нанотехнологий базируются на многочисленных исследованиях различных наноразмерных объектов: графена, нанотрубок, нанопроволок, квантовых точек, металлических наночастиц. Необычные электронные и оптические свойства металлических наночастиц, которые вызваны размерными эффектами, нашли применение в катализе [1], создании биосенсоров [2], медицине [3,4], датчиках газов [5] и т.д.

Одним из популярных объектов для исследований являются золотые наночастицы, история применения которых насчитывает уже не одно столетие. Первые золотые наночастицы были получены в коллоидном растворе. В настоящее время наночастицы на поверхность наносят, например, при напылении золота на поверхность металлов [6-8] и полупроводников [9-11]. Исследованию и различным аспектам применения золотых наночастиц посвящены многочисленные публикации [1,2,4-13]. Так, например, в [13] продемонстрировали изготовление наноотверстий с диаметром $\sim 20 \mathrm{~nm}$ в сапфировой подложке посредством термической обработки с использованием наночастиц $\mathrm{Au}$ в качестве катализаторов процесса создания наноотверстий. Процесс окисления бензилового спирта на адсорбированных пленках наночастиц на поверхностях $\left(\mathrm{ZnO}, \mathrm{Al}_{2} \mathrm{O}_{3}, \mathrm{TiO}_{2}\right.$ и $\left.\mathrm{SiO}_{2}\right)$ с размером $\sim 3 \mathrm{~nm}$ был исследован в [11].
Исследования посвящены не только влиянию размерных эффектов на физико-химические свойства золотых наночастиц, но и тому, как происходит формирование наночастиц, их термической стабильности, как изменяются спектры валентной зоны и остовных уровней в зависимости от размера наночастиц или усредненной толщины золотой пленки наночастиц. Формирование спектра валентной зоны, характерной для массивного золота происходит при напылении более 3 монослоев золота на $\mathrm{Mo} \mathrm{(110)} \mathrm{[7],} \mathrm{TiO}_{2}$ [10], что связано с малыми значениями глубины выхода фотоэлектронов [14]. В [10] было показано, что чем больше размер золотой наночастицы нанесенной на кварцевую подложку, тем спектр валентной зоны ближе к спектру для массивного золота. В [15] был исследован спектр валентной зоны вблизи уровня Ферми золотых наночастиц, напыленных на $\mathrm{SiO}_{2}$, в зависимости от размера наночастиц $(0.3-2.9 \mathrm{~nm})$ и показано, что переход металлизолятор происходит при размере золотых наночастиц более $0.6 \mathrm{~nm}$.

Одним из распространенных методов создания наночастиц заданного размера является прогрев золотой пленки. Так, в [16] показано, что прогрев толстой пленки золота на кварцевой подложке приводит к формированию золотых наночастиц высотой $20 \mathrm{~nm}$ и диаметром $40 \mathrm{~nm}$ за счет поверхностной диффузии. В [17] исследовано влияние температуры отжига и условий формирования пленок золота толщиной $1-100 \mathrm{~nm}$ на $\mathrm{GaN}$-подложке. Показано, что при отжиге в диапазоне 
температур $200-850^{\circ} \mathrm{C}$ можно получить различные наноструктуры от наностержней до нанотреугольников и других полиэдральных структур. В [18] было показано, что нагрев до $700^{\circ} \mathrm{C}$ приводит к увеличению размеров наночастиц $\mathrm{Au}$ в зависимости от подложки: в 1.5 раза для $\mathrm{Au} / \mathrm{Al}_{2} \mathrm{O}_{3}$ и в 5 раз для $\mathrm{Au} / \mathrm{TiO}_{2}$. Похожий результат был получен в [19], где было показано, что наночастицы золота более термически стабильны на $\mathrm{Al}_{2} \mathrm{O}_{3}$, чем на $\mathrm{Fe}_{2} \mathrm{O}_{3}$. С другой стороны, в [20] показано, что тип подложки (окисленные алюминий, титан, кремний и $\mathrm{HOPG}$ ) не влияют на размеры создаваемых наночастиц.

В спектрах рассеяния и поглощения наночастиц золота наблюдаются резонансные пики в видимом и ИКдиапазоне, связанные поверхностными плазмонными состояниями. Такое свойство делает золотые наночастицы одним из важнейших объектов современной нанобиотехнологии $[21,22]$. Положение резонансного пика зависит от ближайшего диэлектрического окружения, формы и размера золотых частиц [23].

В работе была поставлена задача исследования адсорбции небольших (менее долей монослоя атомов натрия) и прогрева на электронную структуру, топографию поверхности и катодолюминесценцию для лучшего понимания процессов трансформации золотых наночастиц.

\section{2. Эксперимент}

В настоящей работе напыление наночастиц золота на поверхность вольфрамовой фольги толщиной $200 \mu \mathrm{m}$ было проведено на установке BOC Edwards Auto 500, предназначенной для вакуумного напыления металлических пленок и покрытий различного функционального назначения.

Фотоэмиссионные исследования были выполнены в Российско-Германской лаборатории на синхротроне HBZ BESSY II (Берлин, Германия) с использованием метода фотоэлектронной спектроскопии (ФЭС) при возбуждении в диапазоне энергий фотонов $80-600 \mathrm{eV}$. Регистрировались фотоэлектроны по нормали к поверхности, возбуждающий пучок падал на поверхность образца под углом $45^{\circ}$. Исследования золотых наночастиц, напыление атомов натрия проводились in situ в вакууме $P<5 \cdot 10^{-10}$ Torr при комнатной температуре. Регистрировались спектры фотоэмиссии в области валентной зоны, а также спектры остовных уровней $\mathrm{Au} 4 f$ и $\mathrm{Na} 2 p$. Полное энергетическое разрешение было $50 \mathrm{meV}$. Для всех приведенных ниже спектров фон был вычтен по методу Ширли.

Спектры катодолюминесценции (КЛ) были получены на электронно-зондовом микроанализаторе CAMEBAX (Сатеса, Франция), оснащенном оптическими спектрометрами оригинальной конструкции. Условия эксперимента: энергия электронов $5 \mathrm{keV}$, ток электронного пучка $50 \mathrm{nA}$, диаметр пучка $5 \mu \mathrm{m}$. При такой энергии пер- вичных электронов катодолюминесценция возбуждается на глубине до $20 \mathrm{~nm}$.

Морфология поверхности образцов была исследована при помощи атомно-силовой микроскопии (АСM) на атомно-силовом микроскопе NTegra-Aura (NT-MDT, Зеленоград, Москва). Использовались стандартные ACM-зонды типа NSG11 с типичной кривизной острия иглы $10 \mathrm{~nm}$.

\section{3. Экспериментальные результаты}

Было исследовано изменение морфологии золотой пленки непосредственно после ее нанесения и после напыления натрия и прогрева. На рис. 1, $a$ приведено характерное АСМ-изображение поверхности вольфрама после нанесения золотой пленки. Видно, что поверхность полностью покрыта золотыми наночастицами. При этом их размер в латеральном направлении составляет порядка $40 \mathrm{~nm}$, а высота может быть оценена на уровне $4-6 \mathrm{~nm}$. На рис. $1, b$ приведено характерное изображение аналогичной пленки после напыления $\mathrm{Na}$ и прогрева. Неоднородность поверхности сильно выросла, произошло объединение наночастиц в зерна с линейными размерами порядка $80 \mathrm{~nm}$ и высотой около $10-20 \mathrm{~nm}$.

Перед фотоэмиссионными исследованиями образцы не прогревались. В спектре при энергии возбуждения $h v=600 \mathrm{eV}$ кроме пиков золота был зарегистрирован небольшой пик углерода. Фотоэмиссии из вольфрамовой подложки не наблюдалось. Атомарно-чистый $\mathrm{Na}$ напылялся на чистую поверхность образца из стандартного источника. Отметим, что за один монослой (ML) Na принимается концентрация $1.0 \cdot 10^{15} \mathrm{atom} / \mathrm{cm}^{2}$, при которой формируется укомплектованный слой атомов Na. Покрытие атомов натрия определялось по ослаблению остовных пиков подложки из нержавеющей стали, к которой крепился исследуемый образец, при энергии возбуждения фотоэмиссии $h v=150 \mathrm{eV}$ по известным значениям глубины выхода фотоэлектронов в работе [14]. Определение величины напыленного покрытия по ослаблению остовных пиков золота приводит к заниженным оценкам, так как известно, что атомы натрия диффундируют в слой золота при напылении [24].

На рис. 2 представлены спектры фотоэмиссии из остовных уровней $\mathrm{Au} 4 f$ для чистой поверхности золотых наночастиц на поверхности вольфрама при энергиях возбуждения $h v=140$ и $600 \mathrm{eV}$. Полная ширина линий $\Gamma=0.70 \mathrm{eV}$ для обеих линий возбуждения. Отметим, что спектры фотоэмиссии из остовных уровней $\mathrm{Au} 4 f$ при $h v=140 \mathrm{eV}$ соответствуют поверхностной фотоэмиссии, так как кинетическая энергия фотоэлектронов близка к минимуму выхода на универсальной кривой выхода фотоэлектронов от кинетической энергии [25]. А спектр фотоэмиссии при энергии возбуждения $h v=600 \mathrm{eV}$ остовного уровня $\mathrm{Au} 4 f$ отражает выход из глубины пленки, т. н. объемной фотоэмиссии. 

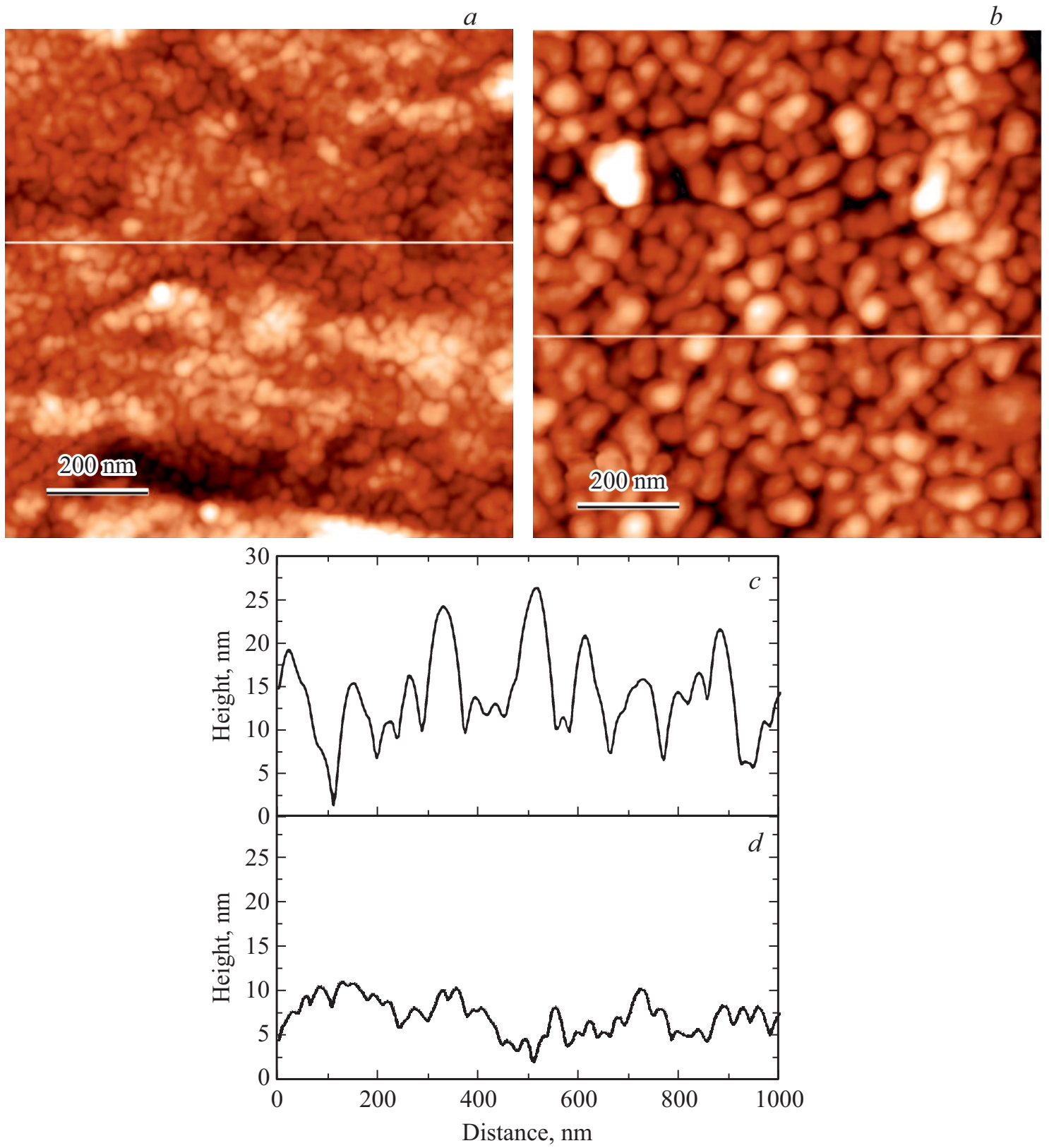

Рис. 1. АСМ-изображение исходной поверхности золотой пленки $(a)$, соответствующий профиль вдоль белой линии $(d)$ и после напыления атомов натрия и прогрева $(b)$ и соответствующий профиль $(c)$.

Нормированные спектры фотоэмиссии в области валентной зоны золотых наночастиц на вольфраме представлены на рис. 3 для энергий возбуждения в диапазоне от 80 до $600 \mathrm{eV}$. Спектры приведены к энергии относительно уровня Ферми $E_{F}$. В области валентной зоны спектр имеет два четко выраженных максимума при энергиях связи $E_{b}=3.0$ и $6.3 \mathrm{eV}$. Форма спектров для всех используемых энергий близка друг к другу, и лишь небольшое отличие спектра при $h v=120 \mathrm{eV}$ можно связать с особенностями спектральной зависимости возбуждения электронов валентной зоны. Отличается лишь интенсивностью, за исключением небольшой особенности при $E_{B}=6 \mathrm{eV}$ для $h v=600 \mathrm{eV}$. Полученные нами результаты хорошо соответствуют результатам, полученным для массивного слоя золота и наночастиц [6-11].

После напыления $0.05 \mathrm{ML}$ натрия на поверхность золотых наночастиц нормированные спектры фотоэмиссии в области валентной зоны представлены на рис. 4 для энергий возбуждения в диапазоне от 80 до $600 \mathrm{eV}$. Форма спектров на первый взгляд остается неизменной. Однако, это не так. Она не изменяется для $h v=600 \mathrm{eV}$, что является логичным, так как при этой энергии возбуждения происходит выход фотоэлектронов с большого диапазона расстояний, т. е. объемной фотоэмиссии. Для остальных энергий возбуждения происходит увели- 

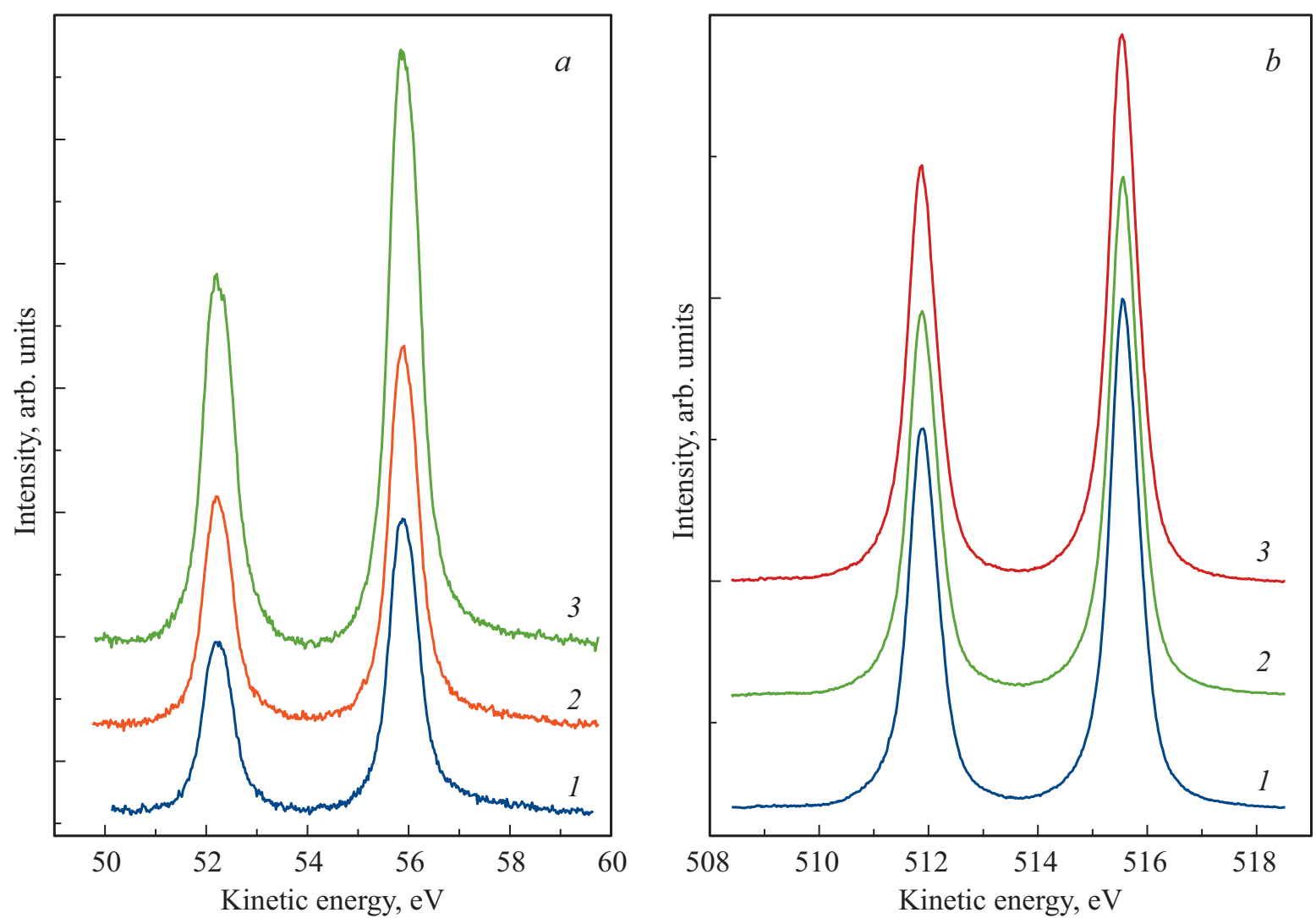

Рис. 2. Спектры нормальной фотоэмиссии остовных уровней $\mathrm{Au} 4 f$. Энергии возбуждения $h v=140(a)$ и $600 \mathrm{eV}(b) .1-$ чистая поверхность, $2-$ с напыленным слоем натрия, $3-$ после прогрева при $T=630 \mathrm{~K}$.

чение фотоэмиссии в области наблюдаемых максимумов до $20 \%$.

Наиболее заметно фотоэмиссия возрастает в области энергий связи $E_{b}=3.3$ и $6.8 \mathrm{eV}$, эти значения близки к максимумам в спектрах валентной зоны для чистой поверхности золотых наночастиц. Это указывает на то, что дополнительный вклад можно связать с увеличением поверхностной фотоэмиссии. Однако, такое увеличение фотоэмиссии при напылении столь малых покрытий атомов щелочного металла ранее не наблюдалось. Поэтому мы связываем это увеличение с перестройкой поверхности, индуцированной адсорбцией натрия, которая приводит к увеличению отношения поверхность/объем относительно исходной пленки. Также на 35\% возрастает интенсивность пика уровней $\mathrm{Au} 4 f$ при энергии возбуждения $h v=140 \mathrm{eV}$ (рис. 3), которая соответствует минимальной глубине выхода фотоэлектронов, и совершенно незначительно для энергии фотонов $h v=600 \mathrm{eV}$, при которой фотоэмиссия происходит из глубины образца, что подтверждает предположение об увеличении отношения поверхность/объем.

На следующем этапе работы слой наночастиц золота с напыленным натрием был прогрет в течение $10 \mathrm{~min}$ при $T=630 \mathrm{~K}$, при этом к образцу было приложено внешнее запирающее положительные ионы электрическое поле $100 \mathrm{~V} / \mathrm{cm}$. Ранее было показано, что такое поле приводит к диффузии положительно заряженных ионов натрия вглубь слоя $\mathrm{NaAu}_{2}$ [24]. Прогрев привел к уменьшению интенсивности пика $\mathrm{Na} 2 p$ в 3 раза при энергии возбуждения $h v=150 \mathrm{eV}$, которая соответствует возбуждению поверхностной фотоэмиссии (рис. 5). Также в 3 раза уменьшился пик $\mathrm{Na} 2 p$ при энергии возбуждения $h v=300 \mathrm{eV}$, которая соответствует возбуждению фотоэмиссии в объеме образца. Это означает, что атомы натрия диффундировали вглубь слоя, и лишь малая часть атомов натрия могла десорбироваться.

Совершенно противоположная картина наблюдалась для фотоэмиссионного пика остовных уровней $\mathrm{Au} 4 f$ (рис. 2). Так пик $\mathrm{Au} 4 f$ при энергии возбуждения $h v=600 \mathrm{eV}$ (объемная фотоэмиссия) остался практически неизменным, что было логично ожидать для исследуемого слоя наночастиц золота и небольшого количества напыленного натрия. Однако пик при энергии возбуждения $h v=140 \mathrm{eV}$ (поверхностная фотоэмиссия) возрос и превысил значения для чистой поверхности в 2 раза, что указывает на увеличение площади поверхности.

На рис. 6 представлены спектры валентной зоны после прогрева при $T=630 \mathrm{~K}$. На них четко видно, что общий вид спектра валентной зоны не изменился. Однако спектры претерпели изменения по-разному: для $h v=600 \mathrm{eV}$ (объемная фотоэмиссия) произошли лишь 
незначительные изменения вблизи и ниже $E_{F}$ на $2 \mathrm{eV}$, а в остальном остался спектр неизменным. Это отражает, что значительных изменений элементного состава в объеме наночастиц не произошло. Однако для поверхностной фотоэмиссии $(h v=80-120 \mathrm{eV})$ зарегистрированы значительные изменения в спектре валентной зоны в диапазоне энергий связи меньших $8.0 \mathrm{eV}$, причем в наибольшей степени эти изменения происходят в области особенностей с максимумами $E_{b}=3.3$ и $6.8 \mathrm{eV}$. И чем меньше энергия возбуждения, тем больше изменений претерпевает вид спектра валентной зоны. Для $h v=80 \mathrm{eV}$ изменения спектра валентной зоны наиболее заметны, так как фотоэлектроны вылетают из области минимального зондирования по глубине образца от поверхности. Фотоэмиссия возрастает в 2 раза, как и для пика остовных уровней $\mathrm{Au} 4 f$ (рис. 2, кривая 3) при энергии возбуждения $h v=140 \mathrm{eV}$, которая соответствует минимальной глубине выхода фотоэлектронов с уровня $\mathrm{Au} 4 f$.

Чтобы понять причину увеличения фотоэмиссии после прогрева рассмотрим, как изменилась морфология поверхности. Как видно из рис. 1, при напылении Na и последующем прогреве образца происходит значитель-

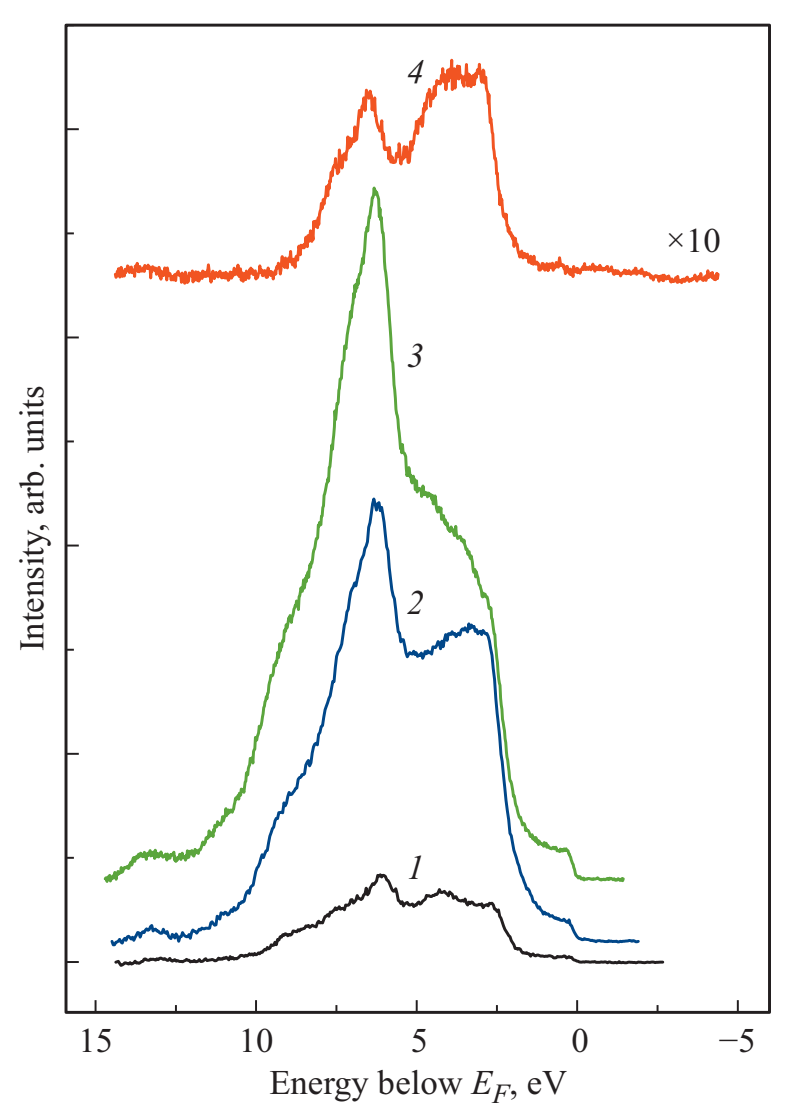

Рис. 3. Нормированные спектры фотоэмиссии в области валентной зоны для чистой поверхности золотых наночастиц на поверхности вольфрама при различных энергиях возбуждения: $1-h v=80 \mathrm{eV}, 2-h v=100 \mathrm{eV}, 3-h v=120 \mathrm{eV}, 4-$ $h v=600 \mathrm{eV}$.

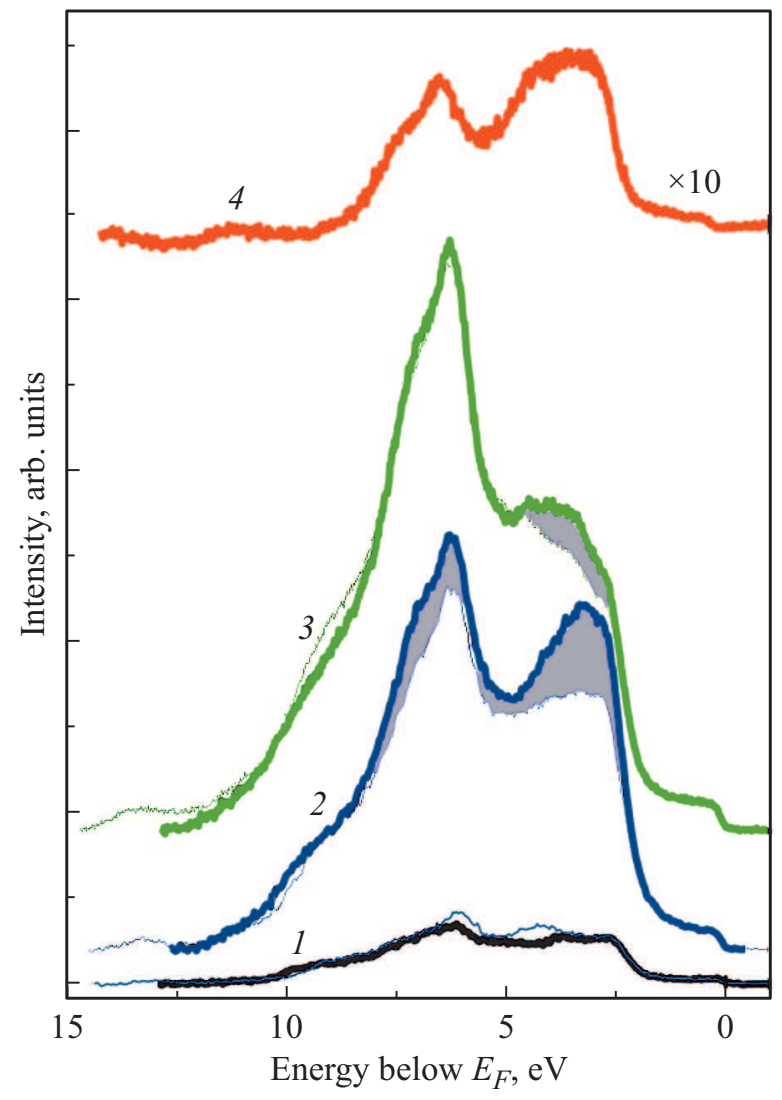

Рис. 4. Нормированные спектры фотоэмиссии в области валентной зоны для поверхности золотых наночастиц на поверхности вольфрама после напыления $0.05 \mathrm{ML}$ натрия при различных энергиях возбуждения: $1-h v=80 \mathrm{eV}, 2-$ $h v=100 \mathrm{eV}, 3-h v=120 \mathrm{eV}, 4-h v=600 \mathrm{eV}$.

ное укрупнение частиц - их латеральные размеры и высота увеличиваются в 2-4 раза. При этом между частицами начинает наблюдаться свободная поверхность, возможно, покрытая несколькими монослоями золота.

Увеличение размера наночастиц означает, что поверхность образца изменяется после адсорбции атомов натрия и прогрева. Для представленных фрагментов АСМ-изображения поверхности на рис. 1 были рассчитаны общая площадь для чистого образца $\left(S_{\text {clean }}\right)$ и после напыления атомов натрия и прогрева $\left(S_{a f t e r}\right)$. Тогда изменение площади наночастиц можно выразить через следующее отношение:

$$
R=\frac{S_{a f t e r}-S}{S_{\text {clean }}-S}
$$

где $S$ - площадь проекции поверхности, равная $1 \mu \mathrm{m}^{2}$. В нашем случае $R=5$.

Наблюдается четкая корреляция между увеличением площади поверхности наночастиц и увеличением поверхностной фотоэмиссии. Следует отметить, что глубина выхода фотоэлектронов $(\lambda)$ из золота при кинетической энергии $80 \mathrm{eV}$ составляет $0.47 \mathrm{~nm}$, при кинетической энергии $600 \mathrm{eV}-0.95 \mathrm{~nm}$ [13]. Считая, что наи- 


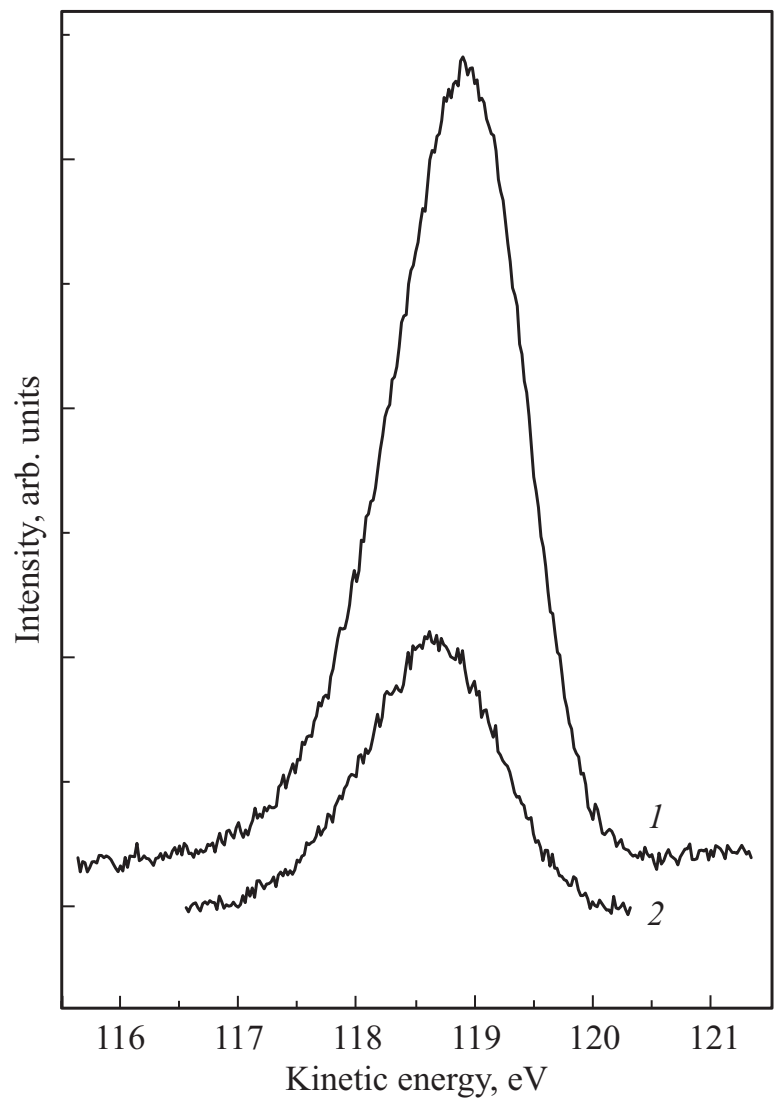

Pис. 5. Спектры нормальной фотоэмиссии остовных уровней $\mathrm{Na} 2 p$. Энергия возбуждения $h v=150 \mathrm{eV} .1-$ с напыленным слоем натрия, 2 - после прогрева при $T=630 \mathrm{~K}$.

больший вклад в фотоэмиссию вносят фотоэлектроны с глубины $\lambda$, при малых кинетических энергиях глубина зондирования составляет 2 слоя атомов золота, т.е. с поверхности и первого приповерхностного слоя атомов золота, а при больших кинетических энергиях глубина зондирования составляет 4 слоя атомов золота, тогда можно сделать вывод, что глубина зондирования намного меньше, чем характерный размер наночастиц. Отсутствие в фотоэмиссионных спектрах пиков, связанных с возбуждением остовных уровней вольфрама, указывает на то, что золотые наночастицы расположены на пленке золота толщиной более 4 атомных слоев или между наблюдаемыми наночастицами в АСМ, располагаются более мелкие наночастицы, которые не видны в АСМ.

На рис. 7. приведены спектры катодолюминесценции исходного образца вольфрама, пленки золота и пленки после нагрева до $630 \mathrm{~K}$ и напыления субмонослойной пленки натрия $0.05 \mathrm{ML}$. По наличию люминесценции в видимом диапазоне можно утверждать, что на поверхности образца наблюдается естественный окисел. Спектр исходного образца вольфрама состоит из двух широких полос с максимумами 2.0 и $2.5 \mathrm{eV}$. Вероятно эти полосы люминесценции связаны с собственными дефектами в пленке естественного окисла вольфрама.

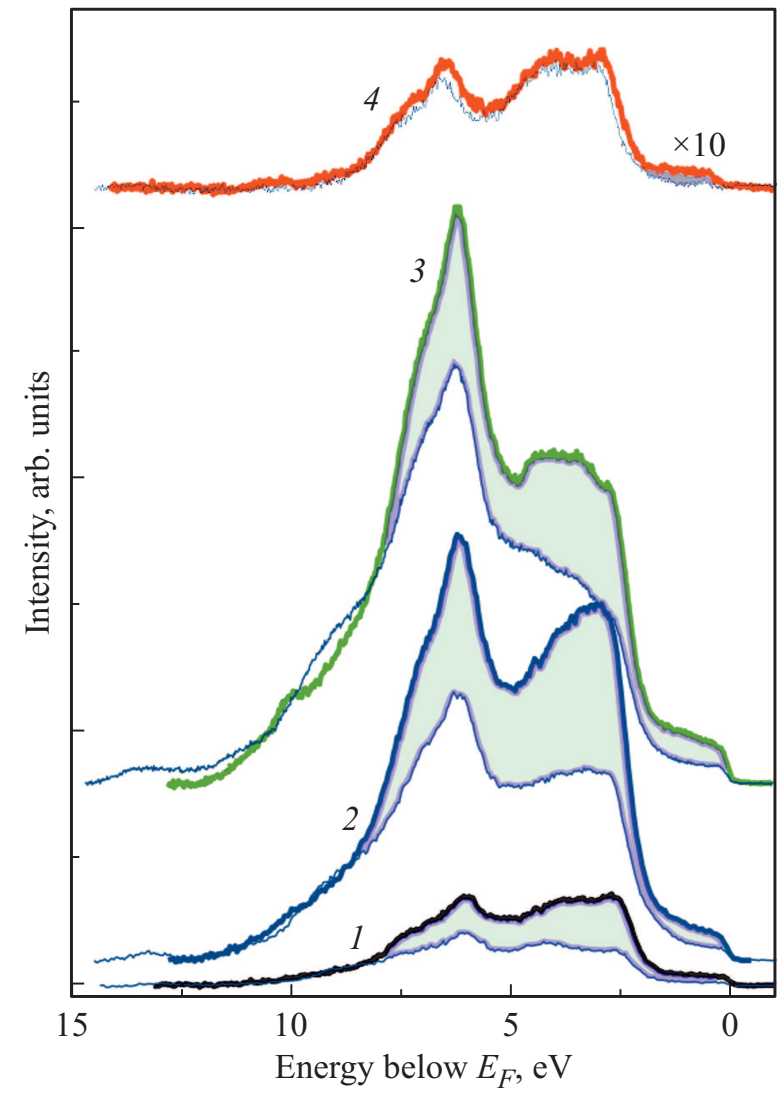

Рис. 6. Нормированные спектры фотоэмиссии в области валентной зоны для поверхности золотых наночастиц на вольфраме после напыления $0.05 \mathrm{ML}$ натрия и прогрева при $T=630 \mathrm{~K}$ при различных энергиях возбуждения: $1-h v=80 \mathrm{eV}, 2-h v=100 \mathrm{eV}, 3-h v=120 \mathrm{eV}, 4-$ $h v=600 \mathrm{eV}$. Заливкой выделены изменения в спектре относительно чистой поверхности.

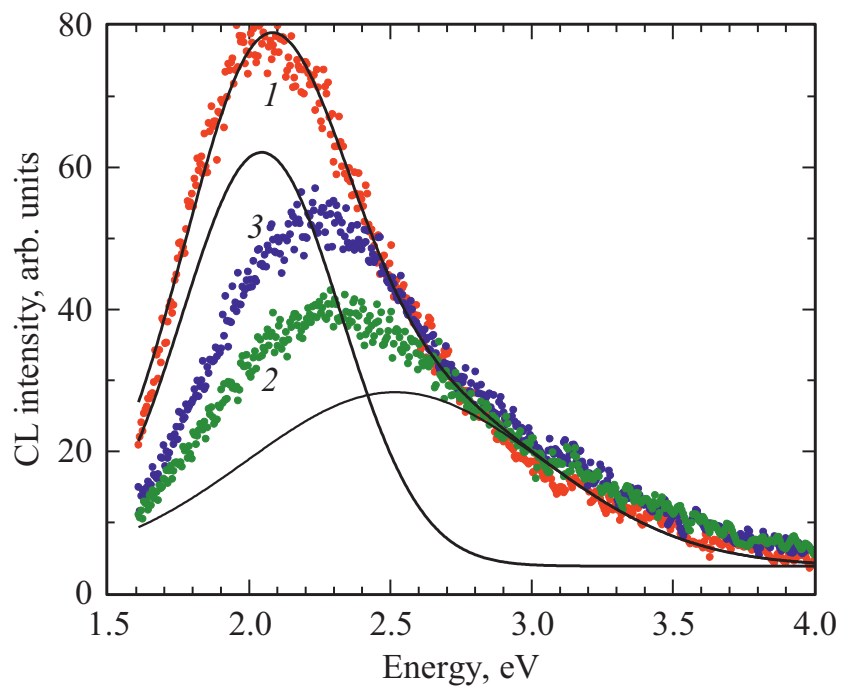

Рис. 7. Спектры катодолюминесценции 1 - исходный образец вольфрама, 2 - пленка золотых наночастиц на вольфраме, 3 - пленка после напыления натрия и нагрева до $630 \mathrm{~K}$. Сплошная линия - аппроксимация спектра катодолюминесценции (1) суммой гауссовых кривых. 




Рис. 8. Рассчитанные спектры поглощения золотой пленки: 1 - пленка золотых наночастиц на вольфраме, 2 - пленка после напыления натрия и нагрева до $630 \mathrm{~K}$. Сплошные линии - аппроксимация соответствующих спектров гауссовой кривой.

После напыления пленки золота, существенно уменьшается интенсивность катодолюминесценции образцов, что возможно связано с поглощением пленки золота. Были рассчитаны спектры поглощения в предположении, что изменения люминесценции связаны именно с поглощением пленки золота (рис. 8).

Как видно из рис. 8 полоса поглощения хорошо аппроксимируется гауссовой кривой, что подтверждает предположение, что изменение спектра связано с поглощением пленки золота. Максимум поглощения в исходной пленке золота приходится на $2.0 \mathrm{eV}(617 \mathrm{~nm})$, после нагрева до $930 \mathrm{~K}$ в вакууме максимум смещается на $1.96 \mathrm{eV}(633 \mathrm{~nm})$ и уменьшается поглощение. Уменьшение поглощения хорошо согласуется с результатами ACM, которые показывают уменьшение площади пленки. В работах $[26,27]$ приведены зависимости максимума полосы поглощения пленки золота в зависимости от размера золотых частиц и агломерации. Такие полосы соответствуют либо частицам с размерами более $150 \mathrm{~nm}$, либо крупным агломератам частиц. Причем сдвиг максимума поглощения в сторону меньших энергий соответствует увеличению размера частиц или агломератов, что согласуется с данными АСМ.

\section{4. Заключение}

Таким образом, в данной работе, впервые исследована электронная структура поверхности наночастиц золота на вольфраме до и после адсорбции атомов натрия и прогрева при $T=630 \mathrm{~K}$. Анализ формы спектров остовных уровней $\mathrm{Au} 4 f$ и $\mathrm{Na} 2 p$ при синхротронном возбуждении в диапазоне энергий фотонов $80-600 \mathrm{eV}$ показал, что происходит изменение в интенсивности фотоэмиссии, так что эмиссия из остовных уровней $\mathrm{Au} 4 f$ возрастает после прогрева при $T=630 \mathrm{~K}$, эмиссия из остовных уровней $\mathrm{Na} 2 p$ уменьшается. Также происходят очень заметные изменения в спектре валентной зоны после прогрева образца: наблюдается резкий рост поверхностной фотоэмиссии до 2 раз. Это связано с увеличением площади поверхности в несколько раз (до 5) после прогрева образца. Наблюдается прямая корреляция между увеличением площади поверхности наночастиц и поверхностной фотоэмиссией. Обнаружено, что прогрев и напыление Na приводит к заметному увеличению размеров наночастиц и частичному освобождению пространства между ними. Показано, что в спектрах КЛ наблюдаются полосы, связанные с люминесценцией естественного окисла вольфрама. Сделано предположение, что изменение спектров связано с поглощением люминесценции пленкой золота. Полученные спектры поглощения полностью согласуются с результатами, полученными методом АСМ.

\section{Благодарности}

Этот исследовательский проект был поддержан русско-немецкой лабораторией на BESSY II. Мы благодарим HZВ за выделение времени пучка синхротронного излучения. Авторы выражают благодарность К.П. Котляру за помощь в подготовке образцов.

\section{Конфликт интересов}

Авторы заявляют, что у них нет конфликта интересов.

\section{Список литературы}

[1] P. Priecel, H.A. Salami, R.H. Padilla, Z. Zhong, J.A.L. Sanchez. Chin. J. Catal. 37, 1619 (2016).

[2] X.-M. Ma, M. Sun, Y. Lin, Y.-J. Liu, F. Luo, L.-H. Guo, B. Qiu, Z.-Y. Lin, G.-N. Chen. Chin. J. Anal. Chem. 46, 1 (2018).

[3] P.G. Jamkhande, N.W. Ghule, A.H. Bamer, M.G. Kalaskar. J. Drug Delivery Sci. Technol. 53, 101174 (2019).

[4] Y. Kumari, G. Kaur, R. Kumar, S.K. Singh, M. Gulati, R. Khursheed, A. Clarisse, K. Gowthamarajan, V.V.S.N.R. Karri, R. Mahalingam, D. Ghosh, A. Awasthi, R. Kumar, A.K. Yadav, B. Kapoor, P.K. Singh, K. Dua, O. Porwal. Adv. Colloid Interf. Sci. 274, 102037 (2019).

[5] G. Korotcenkov, V. Brinzari, B.K. Cho. Microchim. Acta 183, 1033 (2016).

[6] M. Salmeron, S. Ferrer, M. Jazzar, G.A. Somorjai. Phys. Rev. B 28, 1158 (1983).

[7] J.A. Rodriguez, M. Kuhn. Surf. Sci. 330, L657 (1995).

[8] J.J. Kolodziej, T.E. Madey, W. Keister, J.E. Rowe. Phys. Rev. B 62, 5150 (2000).

[9] B. Balamurugana, T. Maruyama. Appl. Phys. Lett. 87, 143105 (2005).

[10] A. Howard, D.N.S. Clark, C.E.J. Mitchell, R.G. Egdell, V.R. Dhanak. Surf. Sci. 518, 210 (2002). 
[11] G. Kumar, L. Tibbitts, J. Newell, B. Panthi, A. Mukhopadhyay, R.M. Rioux, C.J. Pursell, M. Janik, B.D. Chandler. Nature Chem. 10, 268 (2018).

[12] C.D. De Souza, B.R. Nogueira, M.E.C.M. Rostelato. J. Alloys Comp. 798, 714 (2019).

[13] M. Sui, P. Pandey, M.-Yu Li, Q. Zhang, S. Kunwar, J. Lee. Appl. Surf. Sci. 393, 23 (2017).

[14] S. Tanuma, C.J. Powell, D.R. Penn. Surf. Interf. Anal. 43, 689 (2011).

[15] H.S. Kim, S.Y. Shin, S.H. Uhm, J. Han, H.N. Hwang, B. Kim. Chem. Phys. Chem. 10, 1270 (2009).

[16] S. Mao, J. Liu, Y. Pan, J. Lee, Z. Yao, P. Pandey, S. Kunwar, Z. Zhu, W. Shen, L.A. Belfiore, J. Tang. Appl. Surf. Sci. 495, 143575 (2019).

[17] S. Mao, P. Pandey, M.-Y. Li, Q. Zhang, S. Kunwar, J. Lee. J. Mater. Sci. 52, 391(2017).

[18] N. Masoud, T. Partsch, K.P. de Jong, P.E. de Jongh. Gold Bull. 52, 105 (2019).

[19] М.Ю. Смирнов, Е.И. Вовк, А.В. Калинкин, Е.Ю. Герасимов, В.И. Бухтияров. Изв. АН. Сер. хим. 12, 2733(2014).

[20] М.В. Гришин, А.К. Гатин, С.Ю. Сарвадий, Б.Р. Шуб. Хим. безопастность 2, 23 (2018).

[21] H. Liao, C.L. Nehl, J.H. Hafner. Nanomedicine 1, 201(2006).

[22] D.A. Schultz. Curr. Opin. Biotechnol. 14, 13 (2003).

[23] L. Kelly, E. Coronado, L.L. Zhao, G.C. Schatz. J. Phys. Chem. B. 107, 668(2003).

[24] М.В. Кнатько, М.Н. Лапушкин. ЖТФ 83, 51 (2013).

[25] Lindau, W.E. Spicer. J. Electr. Spectroscopy 3, 409 (1974).

[26] V. Chegel, O. Rachkov, A. Lopatynskyi, S. Ishihara, I. Yanchuk, Y. Nemoto, J.P. Hill, K. Ariga. J. Phys. Chem. C 116, 2683 (2012).

[27] Blakey, Z. Merican, K.J. Thurecht. Langmuir 29, 8266 (2013).

Редактор К.В. Емцев 